\title{
Gestão Social nos marcos neoliberais: única alternativa à democracia?
}

\author{
Management in social neoliberal marcos: only alternative to democracy?
}

\author{
Marília Gonçalves Dal Bello*
}

\begin{abstract}
Resumo:
O trabalho aqui apresentado tem como foco a gestão social nos marcos do neoliberalismo nos anos 1970, momento em que é colocada como estratégia para exaltar o mercado como instância de regulação econômica e política da vida social, em detrimento do cercear da participação da sociedade civil como instância participativa, tendo em vista a construção de uma gestão pública democrática. Assim, o objetivo deste trabalho é tecer uma discussão sobre as distorções teóricas e práticas em torno do termo sociedade civil, a fim de elucidar o sentido de participação, como lócus de proposições e disputas que permeiam a construção democrática. Isso se contrapõe a ideia de sociedade civil como sinônimo de solidariedade, voluntariado ou terceiro setor. A metodologia do trabalho associou-se à revisão bibliográfica, cujos referenciais contribuíram para uma apresentação crítica sobre a gestão social. Os resultados aqui apresentados apontam para a necessidade de uma maior consolidação dos espaços públicos e da sociedade civil como atores de fundamental importância para a construção de uma gestão pública democrática.
\end{abstract}

Palavras-chave: Gestão social. Neoliberalismo. Democracia.

\begin{abstract}
:
The work presented here focuses on the social management within the framework of neoliberalism in the 70s, when it is placed as a strategy to lift the market as a body for economic regulation and social policy at the expense of curtailing the participation of civil society as forum for participation in order to build a democratic public. So the objective is to weave a discussion of the theoretical distortions and practices around the term civil society in order to elucidate the meaning of participation as a locus of propositions and disputes that involve the construction of democracy. This contradicts the idea of civil society as synonymous with solidarity, voluntary or third sector. The results presented here point to the need for further consolidation of public spaces and civil society actors as vital for building a democratic public.
\end{abstract}

Keywords: Social management. Neoliberalism. Democracy.

\footnotetext{
* Assistente Social. Docente na Faculdade de Educação, Ciências e Letras de Paranavaí-FAFIPA. Doutoranda pela Pontifícia Universidade Católica de São Paulo-PUC madalbello@hotmail.com
} 


\section{Introdução}

O presente trabalho busca tecer uma análise sobre gestão social, tendo em vista a participação da sociedade civil no espaço público como parte do processo de construção da gestão pública democrática. Para tanto, a discussão em torno da concepção de sociedade civil é de suma importância, no sentido de elucidar distorções teóricas e práticas que se constituem em torno do ideário neoliberal.

A compreensão neoliberal de sociedade civil, como tudo aquilo que está fora da esfera estatal, resgata a lógica da concorrência do mercado e o cidadão consumidor como estratégias necessárias para a garantia de liberdade. O que acaba por reduzir a ideia de liberdade democrática a ideia de consumo, por parte daqueles que, inseridos ao mercado de trabalho, podem fazer. À outra grande parcela da população, em condições precárias de trabalho e renda ou sem trabalho, resta o acesso a serviços precários e focalizados naqueles considerados miseráveis. Na sociedade civil, insere-se ainda o chamado terceiro setor, que voltado à prestação de uma solidariedade empresarial, mediante a oferta de serviços públicos não estatais, lança apelos aos voluntários para a instituição de entidades filantrópicas, como as ONGs para prestarem ajuda aos carentes. O resultado é a despolitização e a redução do Estado frente à garantia de direitos, em um movimento de transferência da cidadania para o âmbito da caridade e da solidariedade.

Se por um lado a intenção neoliberal é a libertação capitalista das amarras econômicas e políticas que possam cercear a acumulação de lucros, por outro a manutenção do Estado democrático é fundamental para a legitimidade da ordem capitalista, que tem no sufrágio universal a sua base de sustentação. A partir dessa dinâmica contraditória do Estado democrático, entende-se, com base em Gramsci, que sociedade civil, longe de resumir-se à prestação de serviços voluntários, associa-se à construção de espaços de mobilização, discussões e disputas de um conjunto heterogêneo de atores e instituições na busca de um projeto hegemônico de classe. Neste sentido, a esfera pública, compreendida como um espaço além do mercado e do privado, constitui o lócus privilegiado para a manifestação daqueles que se propõem a disputas de projetos políticos, seja em defesa de um projeto participativo democrático, seja de um projeto neoliberal. A intenção é a constituição de movimentos e grupos, que, 
detendo poder de força e pressão, consigam introduzir na gestão estatal suas demandas e reivindicações que possam ser concretizadas no âmbito da gestão pública.

\section{Gestão Social no Cenário Neoliberal}

No século passado, a gestão social sustentada pelo Welfare Sate desencadeou a consolidação dos Estados-Nação, vinculados à garantia dos direitos sociais e de projetos universalistas de atenção às necessidades básicas dos cidadãos em países socialistas ou capitalistas. Por cerca de 30 anos, no pós-segunda guerra mundial orientado por raízes keynesianas, o pacto entre classes obteve na combinação entre capitalismo e democracia, políticas sociais, baseada na garantia de pleno emprego, igualdade e cidadania. Nos anos 1980, mais acentuadamente no início dos anos 1990, o definhamento do Welfare State anuncia o desmonte da essência da política social de direito, ou seja, seu caráter universalista e redistributivista. Nas palavras de Netto (2001, p. 68): “[...] a crise do Welfare Sate explicita o fracasso do único ordenamento sócio político que na ordem do capital visou expressamente compatibilizar a dinâmica da acumulação e da valorização capitalista com a garantia de direitos políticos e sociais mínimos [...]".

O Estado sofre um redirecionamento nas suas funções reguladoras, expressas no encolhimento das suas funções legimitadoras, tendo em vista atender a garantia de prosperidade do capital financeiro que, regido por ondas longas com tonalidades expansivas, e/ou de estagnação, em um movimento de tensão entre supercumulação e crise de depressão, é indispensável sem a intervenção política e o apoio financeiro dos Estados nacionais. Outro elemento a ser considerado em relação ao alinhamento dos Estados nacionais na manutenção do capital financeiro associa-se ao aumento da dívida pública, com o investimento dos governos nos títulos emitidos pelo tesouro nacional. Inserida como um dos principais mecanismos para garantia do poder das finanças a dívida pública é o mecanismo de criação de créditos em benefício dos rentistas, em detrimento do endividamento dos governos, gerando assim, entre outras consequências, paralisia das despesas públicas: incentivos de créditos à agricultura, políticas sociais e serviços públicos. Tem-se então um Estado reduzido nas satisfações das necessidades das grandes maiorias, visto que o fundo público é canalizado para alimentar o capital financeiro.

Se por um lado se presencia a instituição de um Estado mínimo nas garantias de 
direitos sociais, com vistas a favorecer o capital financeiro, por outro, Montaño (1999, p. 61) afirma ser essencial a manutenção do Estado democrático, considerado parte fundamental da legimitinadade capitalista, segurada pela incorporação de homens livres, cidadãos por meio da igualdade política. Ou seja, o Estado, para desenvolver, legitimar e perpetuar a "lógica capitalista," incorpora a "lógica democrática". Entretanto o desenvolvimento de direitos trabalhistas e a ampliação da cidadania e da democracia desencadeiam altos custos e conferem amplos poderes às maiorias populares. Assim, mesmo que a intenção não seja eliminar a democracia como componente que garanta legitimidade à ordem capitalista, o foco neoliberal é a eliminação de qualquer interferência democrática no controle do movimento do capital. "O que desejam [neoliberais] e pretendem não é 'reduzir a intervenção do Estado', mas encontrar as condições ótimas (hoje só possíveis com o estreitamento das instituições democráticas) para direcioná-las segundo seus interesses de classe" (PAULO NETTO, 2001).

A saída encontrada para que, na democracia, o capitalismo prospere sem amarras de ordem econômica e/ou política associa-se a passagem da legitimação da esfera do Estado para a esfera da sociedade civil. Entendida como tudo aquilo que está fora da órbita do Estado, a sociedade civil é identificada com o mercado, cuja orientação neoliberal enfatiza a diminuição estatal na oferta de bens e serviços, com vistas ao fortalecimento da concorrência dos mercados (MONTAÑO, 1999).

Paulo Netto (2001, p. 77), ao referir-se ao entendimento sobre neoliberalismo, afirma tratar-se de "[...] Uma argumentação teórica que restaura o mercado como instância mediadora societal elementar e insuperável e uma proposição política que repõe o Estado mínimo como única alternativa e forma para a democracia [...]".

Segundo o autor, o neoliberalismo não se trata de um retorno puro e simples ao "Estado-guarda noturno", conforme os propósitos do liberalismo clássico, uma vez que o almejado não é a eliminação das regulações econômicas por parte do Estado, mas sim a eliminação de mecanismos reguladores que contenham qualquer controle democrático sob o movimento do capital. Neste sentido, a "ofensiva neoliberal" contrapõe-se abertamente à cultura antidemocrática e igualitária, firmada não só na garantia de direitos civis e políticos para todos, mas também pela busca da redução das desigualdades sociais (PAULO NETTO, 2001). 
Preza-se por um Estado mínimo neoliberal que, em favor do mercado, segundo Paulo Netto (2001), assume duas funções restritas: a de prover uma estrutura para o mercado e a de prover serviços que o mercado não pode oferecer. Montaño (1999), ao analisar o contexto das privatizações, observa que a desestatização corresponde, na sua maior parte, a setores empresarias públicos considerados rentáveis e lucrativos. Aqueles entendidos como geradores de déficit ou superavit desprezíveis devem continuar sob administração estatal. Assim, aquelas empresas públicas tidas como rentáveis e, portanto, de interesse econômico devem ser retiradas da órbita estatal, lócus em que o controle e o lucro são regidos em âmbito democrático.

Em um movimento denominado por Carvalho (1999) de Welfare dualizado, o mercado voltado para atender aqueles com poder de compra especializa-se no atendimento ao cidadão cliente, e o Estado, volta-se para atender precariamente aos marginalizados. Assim, diante da miséria, uma renda mínima deveria caber aos pauperizados, por meio de mecanismo gerido estatalmente (PAULO NETTO, 2001).

Ao passo que se observa um desmantelamento das proteções sociais dos sistemas e seguridade e assistência social pública, bem como das políticas de subsídio ao consumo de bens básicos, como energia elétrica e telefonia, constata-se um apelo ao consumo por serviços sociais a serem adquiridos no âmbito mercadológico.

A partir desse contexto, Carvalho (1999) menciona a tensão entre a eficiência e a equidade que permeiam a gestão social: os processos de privatização e publicização de atividades não exclusivas do Estado prometem maior eficiência no gasto social, porém não asseguram necessariamente equidade, uma vez que se mantém o desafio de garantir, sob as privatizações, que cidadãos consumam com menor custo e maior qualidade.

A partir da perspectiva neoliberal, a sociedade civil, ao ter como interface as empresas, abrange a caridade como função empresarial para com os trabalhadores que nelas se inserem, consumidores ou vizinhos. Entra em cena o que Montaño (1999) chama de "nova esquerda" que, além do Estado e do mercado, evidencia-se como terceiro setor, destinado ao desenvolvimento de atividades públicas em âmbito estatal. 
Esse processo de participação da sociedade civil no tratamento das seqüelas da questão social ${ }^{1}$ é considerado pela nova esquerda e pela intelectualidade especializada como fundamento da emergência e/ou expansão do chamado terceiro setor - conjunto de instituições, ONGs, fundações [...] que, desempenhando funções públicas, encontram-se fora do Estado, no espaço de intersecção entre este e o mercado, porém sem declarar fins lucrativos (MONTAÑO, 1999, p. 66).

A construção do projeto neoliberal, ao ter o mercado como organizador da vida social e política, transforma os governos em provedores de serviços e os cidadãos em clientes usuários, com os quais é preciso ter sensibilidade com respeito as suas demandas e eficiência no seu atendimento. A participação da sociedade civil é inserida, nesse contexto, como instância capacitada para fornecer informações qualificadas sobre as demandas sociais e assumir com eficiência a execução das políticas públicas voltadas para essas demandas (DAGNINO; OLVERA; PANFICHI, 2006, p. 54).

Ao referir-se ao embate entre o projeto neoliberal e o projeto democrático, Dagnino, Olvera e Panfichi (2006) afirmam que ambos baseiam-se em referenciais de construção de cidadania, participação e na ideia de sociedade civil. Esses referenciais são comuns, mas abrigam significados bastante distintos, obscurecidos pelo emprego de uma linguagem que dilui diferenças e reduz antagonismos. "Nesse obscurecimento se constroem sub-repticiamente os canais por onde avançam as concepções neoliberais, que passam a ocupar terrenos insuspeitos" (DAGNINO; OLVERA; PANFICHI, 2006, p. 17).

Nessa mesma linha de raciocínio, a autora afirma ser a cidadania remetida para a lógica do mercado, em um movimento de desresponsabilização progressiva do Estado ao seu papel de provedor de direitos, agora representado por entidades filantrópicas e voluntariados, nos quais o significado da expressão "sociedade civil" acaba por restringerse a organizações como as ONG, ou simplesmente reduzida a meros sinônimos de terceiro setor. "Como conseqüência, a pobreza, a desigualdade estão sendo retiradas da arena política e do seu domínio próprio, o da justiça, igualdade e cidadania" (DAGNINO; OLVERA; PANFICHI, 2006).

Dagnino, Olvera e Panfichi (2006), ao citarem Oliveira, equiparam o neoliberalismo

\footnotetext{
${ }^{1}$ Entende-se por questão social o conjunto das expressões das desigualdades da sociedade capitalista madura, associada à monopolização do trabalho socialmente produzido por uma parte da sociedade (IAMAMOTO, 2006, p. 27).
} 
a uma forma de "totalitarismo", assentada na tríade "privatização do público", "destituição da fala" e "anulação da política". Os resultados apontam para um contexto excludente, entendendo a exclusão social não como uma nova "questão social", mas como uma "velha questão social" que se acirra e adquire novas reconfigurações diante do agravamento da exploração e das desigualdades sociais frente ao enorme crescimento dos segmentos sociais excluídos dos mercados, abandonados e desprezados por serem considerados como sobrantes da lógica de acumulação de capitais. Trata-se, assim, não de um fenômeno recente, vinculado ao esgotamento do Estado de Bem-Estar Social, associado à inadaptação dos antigos métodos de gestão do social, como pressupõe Robert Castel, mas refere-se a um conceito entendido como expressão da relação contraditória capital e trabalho e das desigualdades e lutas sociais historicamente problematizadas (IAMAMOTO, 2006).

Nas cidades, tais diferenças se expressam e produzem rearticulação de territórios por onde circulam capitais, bens, mercadorias, serviços e também populações em situações diversas de emprego, desemprego e exclusão do mercado de trabalho (TELLES, 2007). Nos países periféricos, dentre os quais o Brasil, ao contrário do que aconteceu nos países centrais, o Estado não criou condições para a reprodução da totalidade da força de trabalho e nem estendeu ao conjunto dos trabalhadores os direitos à cidadania. Isso contribuiu para um agravamento das expressões da questão social, evidenciada nos anos 1990, por um amplo processo de segregação social de grande contingentes populacionais com limitadas possibilidades de acesso a bens e serviços urbanos e com restrita mobilidade social. Nas palavras da autora:

As cidades passam a ser o cenário de reconfiguração dos espaços urbanos redesenhados pelo agravamento da questão social [...], pelas diferentes formas de precarização do trabalho e explosão do desemprego, deteriorização dos espaços coletivos, privatização dos serviços públicos, pelo estabelecimento de novas formas de segregação e violência urbana, pelos novos circuitos de pobreza e riqueza que redefinem os tradicionais modelos centro e periferia (RAICHELIS, 2006, p. 33).

Neste sentido, Dagnino, Olivera e Panfichia (2006) chamam a atenção para a necessidade de retomada do projeto democrático participativo como mecanismo de 
contraposição ao projeto neoliberal e retomada do Estado enquanto instância de disputas e conflitos rumo à construção democrática. Embora a política pública seja regulada e frequentemente provida pelo Estado, ela também engloba demandas, escolhas e decisões privadas, podendo e devendo ser confrontada pelos cidadãos por meio do controle democrático. Logo toda política pública compromete sim o Estado na garantia de direitos, mas compromete também a sociedade civil na defesa da institucionalidade legal e integridade dessa política ante os seguintes eventos: assédio de interesses particulares e partidários; clientelismo, submissão da política social a interesses mercantis.

Assim, é necessário que se elucide o conceito de sociedade civil, a fim de ultrapassar a concepção mercadológica conferida pelo neoliberalismo, que submete a cidadania à liberdade de consumo e a participação à prestação de serviços solidários aos carentes. A intenção é aqui resgatar o conceito de sociedade civil, tendo em vista a valorização da inserção de sujeitos e atores na arena democrática, junto à esfera pública, no sentido de fortalecer a participação como mecanismo de concretização de uma gestão pública democrática.

\section{Sociedade Civil e a construção da Gestão Pública Democrática}

Segundo Carvalho (1999), por gestão social entende-se a gestão das ações sociais públicas, ou seja, das demandas e necessidades dos cidadãos. Assim, a política social e os projetos constituem canais de resposta a essas demandas. As prioridades contempladas pelas políticas públicas, embora decididas pelo Estado, nascem na sociedade civil e passam a compor a agenda estatal quando se constituem em demanda reivindicada por grupos com força e pressão capazes de introduzi-la na arena pública.

Por essa razão, é importante aqui destacar o conceito de sociedade civil, descrito por Coutinho (apud DURIGUETO, 2005), a partir da concepção de Gramsci, para quem a sociedade civil é o espaço em que se manifestam a organização e a representação de interesses dos diferentes grupos sociais, como associações, partidos, sindicatos, entre outros. É entendida ainda como esfera da elaboração e/ou difusão dos valores culturais e ideologias como atividades culturais, meios de comunicação entre outros. Constitui-se assim uma das esferas sociais em que as classes organizam e defendem seus interesses, em que embrenham na luta e na defesa de seus anseios com a finalidade de construir 
projetos hegemônico de classe. O que exige uma práxis política, consciente, coletiva e articulada das classes subalternas, representantes dos interesses populares articulados e direcionados para um mesmo fim: o bem comum, o interesse público.

Montaño (1999), ao reportar-se a Gramasci, retoma a concepção de Estado marxista atrelada às realidades atuais, momento em que se presencia uma intensa socialização política, que resultou na conquista do voto, na criação de partidos políticos de massa e na organização sindical e ainda nos movimentos sociais e nas organizações comunitárias.

Desenvolve-se assim a idéia de um Estado mais abrangente do que o mero "comitê" burguês para a opressão do proletariado. Nesse sentido, a "esfera política 'restrita' que era própria dos Estado elitistas - tanto autoritários quanto liberais - cede progressivamente lugar a uma nova esfera pública 'ampliada', caracterizada pelo protagonismo de amplas e crescentes organizações de massa (MONTAÑO, 1999, p. 50).

Assim, segundo Montaño (1999), há em Gramsci a manutenção da ideia de Estado restrito, associado ao caráter de classe e sua função opressora, que é superado e acrescido de novas determinações, que são: a sociedade política, vinculada à função coercitiva; e a sociedade civil, entendida como espaço da superestrutura, cuja busca é a hegemonia mediante o consenso. Isso, conforme Silva (2004), implica um compromisso do Estado com a administração das demandas e necessidades dos cidadãos mediante a oferta de política social, programas e projetos estratégicos e consequentes no âmbito público, com vistas à garantia de direitos. A gestão social é, então, entendida pelo autor, como um conjunto de estratégias voltadas para a reprodução da vida social no âmbito dos serviços, na esfera do consumo social, de modo a não se submeter à lógica mercantil.

Ainda de acordo com Silva (2004), a política social é compreendida como uma arena de confronto de interesses contraditórios direcionados para o acesso à riqueza socialmente produzida. É entendida também a partir de um processo contraditório permanente com a política econômica, uma vez que confere primazia às necessidades sociais, enquanto esta última se volta para fomentar a acumulação e a rentabilidade na esfera do mercado. Combinam-se, então, as duas funções básicas do Estado capitalista: criar condições que favoreçam a acumulação capitalista e articular mecanismos de 
legitimação da ordem social e econômica.

Para Dagnino, Olvera e Panfichi (2006), a construção democrática, permeada por conflitos e tensões, pressupõe a disputa de projetos políticos distintos, polarizados pelo projeto neolieberal e democrático participativo que, ao traduzir diferentes visões sobre a construção democrática, dotam de sentido a luta política. Ao retomar o pensamento de Gramsci, os autores referem-se à noção de projeto político como o conjunto de crenças, interesses, valores, concepção de mundo e representação, o qual, estruturado por escolhas, expressa a ação política de diferentes sujeitos.

Neste sentido, os autores ressaltam a importância da concepção de heterogeneidade, entendida a partir de um conjunto de diversos atores civis, incluindo instituições como sindicatos, associações, entre outras, que, ao dispor de diversas identidades, grande pluralidade de práticas e diferentes formas de relação com o Estado, embrenham-se em uma arena de disputas, demarcada pelas correlações de forças, articulações e por múltiplos conflitos. Em referência a Gramsci, os autores afirmam ser a sociedade civil, fundamental para pensar o Estado, uma vez que a ação política não se limita à sociedade política, mas é parte da própria sociedade civil, cujos atores, ao defenderem projetos na esfera pública e desenvolverem a ação coletiva, estão fazendo política, disputando espaços de poder e orientando a política pública. Assim, a ideia de Estado deve ultrapassar a concepção que o restringe a administração homogênea, permeada por instituições governamentais, a fim de concebê-lo como espaço de inserção dos partidos no governo, no parlamento e nos governos locais e regionais. Tal entendimento faz-se necessário para que se preservem as mediações entre a sociedade civil e o Estado, com possibilidades de cooperação ou de confronto.

\footnotetext{
Para que a democracia tenha maiores possibilidades de se consolidar, parece ser necessária a existência de uma forte correspondência entre um projeto democrático da sociedade civil e projetos políticos afins na esfera da sociedade política (DAGNINO; OLVERA; PANFICHI, 2006, p. 38).
}

A construção do projeto democrático-participativo, ao pressupor a participação da sociedade como fundante para a busca da igualdade e a concretização da cidadania no âmbito das políticas públicas, associa-se a um processo de desprivatização do Estado, permeável ao interesse público, por meio dos canais de participação da sociedade. Além 
dos espaços de participação com vistas à tomada de decisão, Dagnino, Olvera e Panfichi (2006) destacam também espaços de participação, com vistas ao controle da sociedade sobre o Estado, como são as Ouvidorias e o Orçamento Participativo.

Wanderley e Raichelis (2009), ao se remeterem à concepção de esfera pública, situam-na como estratégia para o fortalecimento da democracia. Para os autores, a esfera pública é entendida como inerente à democracia, cujo princípio organizativo associa-se à liberdade de expressão política e cultural, em espaço aberto a todos aqueles que se autorizam a falar publicamente. $O$ conceito de público remete, portanto, ao interesse de todos e ao reconhecimento do direito de todos à participação na esfera pública. Ultrapassa, portanto, o estatal ou o privado.

Assim, a expressão esfera pública [...] é aqui adotada num significado abrangente que engloba as relações entre o econômico e o político, o estatal e o privado, o público não estatal. A esfera pública é concebida como inerente à democracia, cujo princípio organizativo está jungido à liberdade de expressão, contendo dimensões políticas e culturais, espaço aberto no qual se exprimem todos aqueles que se autorizem a falar publicamente (WANDERLEY; RAICHELIS, 2009, p. 9).

Ao definirem as linhas norteadoras para a análise de público, Raichelis e Wanderley também pontuam o seguinte conjunto dinâmico e articulado de ideias: visibilidade social: supõe transparência e publicidade das informações que orientam as ações e deliberações nos espaços públicos, de governos e dos diferentes atores sociais; controle social, que implica o acesso a informações que viabilizem a participação da sociedade civil junto às instituições governamentais, e ainda a fiscalização de decisões segundo pactuações; representação de interesse coletivo, que é um conjunto de sujeitos políticos ativos que, na cena pública, traduza interesses coletivos; democratização que remete à ampliação dos fóruns de debate e decisão política, além daqueles tradicionais já existentes; cultura pública, supondo o enfrentamento ao autoritarismo social e da "cultura privatista" de apropriação do público pelo privado, o que pressupõe interesses reconhecidos, representados e negociados no espaço visível da esfera pública.

Durigueto (2005), ao analisar e propor a construção de "uma nova esfera pública não estatal", observa os conselhos de direito como espaços de uma "cultura democrática," permeados por diversos atores e instituições, como as ONGs, entidades 
profissionais, entre outros, os quais disputam interesses de demandas, ampliando a legitimidade do direito. "Dessa forma, a sociedade civil (transmutada em esfera pública) é vista como uma esfera que transcende a lógica estatal e privada tanto em relação aos interesses que representa quanto em relação à sua dinâmica político-organizativa" (WANDERLEY; RAICHELIS, 2009, p. 94).

Neste sentido, a defesa é para que a participação não se volte para ocupar o espaço da desresponsabilização estatal no âmbito da filantropia e prestação de serviços voluntários, visando a práticas solidárias para os pobres, mas para que se consolidem movimentos e organizações da sociedade civil voltados para a luta pela ampliação de direitos, como garantia de cidadania no âmbito da construção da gestão pública democrática.

\section{Considerações Finais}

A concepção neoliberal de gestão social, que sob o comando de um Estado mínimo exalta o mercado como única alternativa para a democracia, em detrimento da desresponsabilização do Estado com a garantia de direitos sociais, é aqui pensada a partir da lógica democrática em que a sociedade civil é considerada parte fundante para pressionar o Estado a consolidar uma gestão social voltada para a garantia de políticas sociais com perspectivas universalistas e igualitárias segundo preceitos cidadãos. Ao considerar esse contexto, o presente trabalho aponta para a necessária desconfiança do uso do conceito de sociedade civil, tendo em vista as distorções trazidas com a perspectiva neoliberal que busca atrelar sociedade civil à ideia de consumo e/ou de prestação de serviços. Aborda ainda a sociedade civil organizada, norteada por um projeto político, com vistas à construção democrática como parte essencial para a concretização da gestão social, de modo a reduzir os interesses privatistas que permeiam o Estado democrático.

\section{Referências}

CARVALHO, M. C. B. Gestão Social: alguns apontamentos para o debate. In: RICO, E. M.; RAICHELIS, R. (Org.). Gestão Social uma questão em debate. São Paulo: Editora Cortez, 1999. 
DAGNINO, E.; OLVERA, A. J; PANFICHI, A. (Org.). A disputa pela construção democrática na América Latina. Campinas: Paz e Terra, 2006.

DURIGUETO, M. L. Sociedade Civil, esfera pública, terceiro setor. A dança dos conceitos. Revista Serviço Social e Sociedade, São Paulo, n. 81, 2005.

IAMAMOTO, Marilda Vilela. Trabalho e indivíduo social: um estudo sobre a condição operária na agroindústria canavieira paulista. 2. ed. São Paulo: Cortez, 2006.

MONTAÑO, C. Das "lógicas do Estado" às "lógicas da sociedade civil": Estado e "terceiro setor" em questão. Revista Serviço Social e Sociedade, São Paulo, ano XX, n. 59, 1999.

PAULO NETTO, J. Crise do socialismo e ofensiva neoliberal. São Paulo: Cortez, 2001.

RAICHELIS, Raquel. Gestão pública e a questão social na grande cidade. Lua Nova, São Paulo, n. 69, p. 13-48, 2006.

SILVA, M.O.S Avaliação de políticas e programas sociais e cidadania: pela ultrapassagem do modelo funcionalista clássico. In: SILVA, M.O.S ( Org) Avaliação de políticas e programas Sociais: teoria e prática. São Paulo: Editora Veras, 2001.

TELLES, V. S. Pontos e linhas de uma descrição da cidade: trajetórias urbanas e seus territórios. In: FRANCISCO, E. M. V; ALMEIDA, C. C. L. Trabalho, território, cultura: novos prismas para o debate das políticas públicas. Rio de Janeiro: Cortez, 2007.

WANDERLEY, L. E; RAICHELIS. R. (Org.). A cidade de São Paulo: relações internacionais e gestão púbica. São Paulo: Educ, 2009.

Recebido em: 15/11/2010

Aprovado em: 20/12/2010 